\title{
Regional changes in catecholamine content of the pregnant uterus
}

\author{
S. J. Arkinstall and C. T. Jones \\ Nuffield Institute for Medical Research, University of Oxford, Headley Way, Headington, \\ Oxford $O X 39 D S, U . K$.
}

\begin{abstract}
Summary. High-pressure liquid chromatography with electrochemical detection was used to identify and measure catecholamines in rat, rabbit, sheep, guinea-pig and human uteri and follow changes with pregnancy. Noradrenaline was consistently the major catecholamine and pregnancy caused a regionally specific fall in its concentration which, in rat, rabbit and guinea-pig, was associated with a decline in total content. Adrenaline was undetectable ( $<10 \mathrm{pmol} / \mathrm{g}$ myometrium) in all species and at all gestational ages studied. Dopamine and its metabolite 3,4-dihydroxyphenylacetic acid (DOPAC) were detected at high concentrations in guinea-pig and particularly sheep uterus. In guinea-pig uterus the dopamine/DOPAC ratio fell dramatically with pregnancy, suggesting that increased quantities of dopamine were released and catabolized. The dopamine/noradrenaline ratios suggested that dopamine is stored with noradrenaline in adrenergic neurones in guinea-pig myometrium and within an additional neuronal or cellular store(s) in sheep uterus.
\end{abstract}

\section{Introduction}

The mammalian uterus receives a well developed adrenergic supply consisting of classical long neurones innervating predominantly the vasculature, and a unique system of short neurones mostly associated with the myometrium. These originate in lumbar and mesenteric ganglia, and peripheral sympathetic ganglia at and around the utero-vaginal junction respectively. The importance of short adrenergic neurones is unknown but the ability of steroid hormones to influence their transmitter metabolism may enable them to respond specifically to physiological conditions such as pregnancy (Sjoberg, 1967; Rosengren \& Sjoberg, 1968; Falck, Owman, Rosengren \& Sjoberg, 1969; Owman, Sjoberg \& Sjostrand, 1974; Thorbert, Batra, Owman, Rosengren \& Sjoberg, 1976; Thorbert, 1978). Neuronal or exogenous noradrenaline acting via alpha- and beta-adrenoreceptors has been reported to contract (Zuspan, Cibils \& Pose, 1962; Miller \& Marshall, 1965; Isaac \& Pennefather, 1969; Rexroad \& Barb, 1978) and relax (Miller \& Marshall, 1965; Bengtsson, 1978; Elmer, Alm \& Thorbert, 1980) uterine smooth muscle depending on animal species and hormonal state. Adrenergic stimulation also indirectly influences myometrial contractility by increasing sensitivity to oxytocin (Russe \& Marshall, 1970). However, the precise function, if any, of the sympathetic innervation in controlling myometrial contractility remains unknown.

Uterine adrenergic innervation and regional changes with pregnancy have been demonstrated by histofluorescence in many species. Fluorometric determination of myometrial noradrenaline has confirmed these data, which suggest a regionally specific depletion of neuronal noradrenaline towards term (Sjoberg, 1967; Owman, Alm, Rosengren, Sjoberg \& Thorbert, 1975; Thorbert, 1978; Thorbert, Alm, Bjorklund, Owman \& Sjoberg, 1979; More \& Nedjar, 1984). However, because of the similar spectral characteristics of many fluorescent catechol derivatives (Shore \& Olin, 1958; Iversen, 1967; Swedin \& Brudin, 1968), such studies may not provide accurate identification and 
measurement of specific catecholamines. Indeed, this may account for the contradictory reports on the presence of both adrenaline and dopamine within the female reproductive tract (Cha, Lee, Rudzik \& Miller, 1965; Swedin \& Brudin, 1968; Thorbert, Alm \& Rosengren, 1978).

The physiological mechanisms underlying uterine quiescence during pregnancy and increased motility at parturition are unknown. Since adrenaline has been reported to be a powerful relaxant of uterine smooth muscle (Zuspan et al., 1962) and dopamine to increase intrauterine pressure (Fishburne et al., 1980; Urban, Radwan, Laudanski \& Akerlund, 1982), and because both have been detected in high concentrations in the uteri of several species (Wurtman, Axelrod \& Kopin, 1963; Cha et al., 1965; Swedin \& Brudin, 1968; Rexroad \& Barb, 1978; Lackovic, Rezja \& Neff, 1982), it is important to establish whether these catecholamines are potential regulators of uterine activity. Therefore, in a study of the potential significance of catecholamines in the control of myometrial contractility, changes in uterine catecholamine content during pregnancy have been measured in animals of various species.

\section{Materials and Methods}

Dated pregnant Sprague-Dawley rats and New Zealand White rabbits were purchased from Olac (Bicester, Oxfordshire, U.K.) and Ranch Rabbits (Crawley Down, Sussex, U.K.) respectively. Dated pregnant Dunkin-Hartley guinea-pigs were bred in our own animal house (Elvidge, 1972). Sheep uterine samples were obtained from non-pregnant and 125-135-day unilaterally pregnant animals. All animals were virgin or primigravid. Isthmic myometrium was obtained from normally menstruating women undergoing abdominal hysterectomy, and from patients subject to Caesarean section at 39-41 weeks gestation. All women were multiparous with 1-3 previous pregnancies. When possible, regionally specific samples were taken from animal uteri. The nomenclature previously cited (Thorbert, 1978) is used, so that myometrium from immediately around the developing fetus is termed perifetal and that from between fetuses (while distinguishable) parafetal. Tissue taken from the last $5 \mathrm{~mm}$ adjacent to the oviduct is termed tubal myometrium. In guinea-pig a regional study was undertaken with whole uteri sectioned serially from one tubal end to the other, with each sample analysed independently. Whole guinea-pig uteri after parturition were also analysed.

Guinea-pigs were killed by cervical dislocation, rats and rabbits by a blow to the head. Sheep were killed by use of an humane killer. Whole uteri (guinea-pig, rat, rabbit) or uterine samples (sheep, human) were excised and placed on ice, stripped of endometrium, dried by blotting, weighed and finely minced with scissors. The myometrium was homogenized in 2 volumes of icecold 0.4-M-perchloric acid containing 2-mM-sodium metabisulphite and a quantity of 3,4dihydroxybenzylamine (DHBA) as internal standard (appropriate for the endogenous catecholamine concentrations) for $4 \times 30 \mathrm{sec}$ using an Ultra-Turrax homogenizer (The Scientific Instrument Centre Ltd, London, U.K.) at $20000 \mathrm{rev} . / \mathrm{min}$. After centrifugation at $70000 \mathrm{~g}$ for 30 min at $2^{\circ} \mathrm{C}$ the pellet was re-extracted with 1 volume of perchloric acid and the supernatants were pooled. The $\mathrm{pH}$ was adjusted to $4-5$ with $10 \%(\mathrm{w} / \mathrm{v})$ potassium hydroxide. Potassium perchlorate precipitate was removed and the catecholamines were extracted from $0.5 \mathrm{ml}$ supernatant for $30 \mathrm{~min}$ with $30 \mathrm{mg}$ neutral alumina (Sigma; activity grade 1) in the presence of $0.05 \mathrm{ml} 10 \mathrm{~mm}$-sodium metabisulphite and $1.0 \mathrm{ml} 0.5 \mathrm{M}$ Tris $-\mathrm{HCl} \mathrm{pH} 8.6$ containing $2 \%(\mathrm{w} / \mathrm{v})$ ethylenediaminetetra-acetic acid (EDTA). Alumina was then sedimented at $1000 \mathrm{~g}$ for $15 \mathrm{~min}$ and washed 3 times in $1.0 \mathrm{ml}$ $\mathrm{H}_{2} \mathrm{O}$. Catecholamines were eluted with $0.2 \mathrm{ml} 0 \cdot 1 \mathrm{M}$-perchloric acid containing $0 \cdot 1 \mathrm{~mm}$-sodium metabisulphite and $0.05 \mathrm{ml}$ was injected directly onto the high-pressure liquid chromatography (HPLC) analytical column

The HPLC with an electrochemical detection system consisted of a solvent pump (M45; Waters Associates Inc., Milford, MA, U.S.A.), valve injector with $0.05 \mathrm{ml}$ constant volume injection loop 
(Specac, Orpington, Kent, U.K.), precolumn filter (Jones Chromatography Ltd, Llanbradach, Glamorgan, U.K.) and a Spherisorb ODS $(25 \mathrm{~cm} \times 5 \mathrm{~mm}$ i.d., $5 \mu \mathrm{m}$ particle size $)$ analytical column (HPLC Technology Ltd, Macclesfield, Cheshire, U.K.). Catecholamines were detected using a flow-through electrochemical cell with a glassy carbon working electrode set at $+0.72 \mathrm{~V}$ and electronic control module (Model LC-2A, Bioanalytical Systems Inc., W. Lafayette, IN, U.S.A.). The catechols were eluted from the column at $1.0 \mathrm{ml} / \mathrm{min}$ with $1 \%(\mathrm{w} / \mathrm{v})$ citric acid monohydrate, $1 \%(\mathrm{w} / \mathrm{v})$ sodium dihydrogen phosphate dihydrate, $1 \%(\mathrm{w} / \mathrm{v})$ disodium hydrogen phosphate, 1 mM-EDTA, $0.048 \%$ (w/v) 1-octane sulphonic acid and $5 \%(\mathrm{v} / \mathrm{v})$ methanol, adjusted to pH 2.80-2.81 with phosphoric acid and degassed with helium. This system gives good resolution of catecholamines extracted by the alumina (Text-fig. 1).

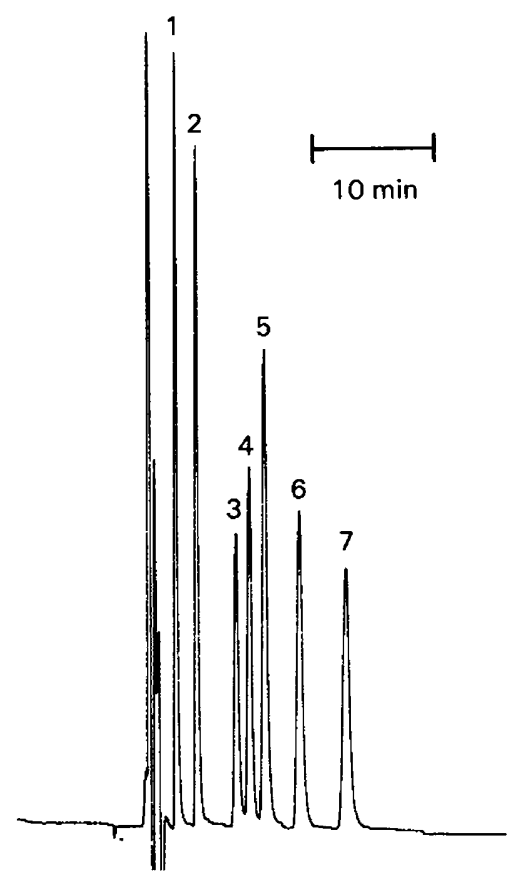

Text-fig. 1. HPLC chromatogram showing separation of catecholamine standards. Peaks represent $10 \mathrm{pmol}$ injected catecholamine: (1) 3,4-dihydroxyphenylglycol; (2) noradrenaline; (3) adrenaline; (4) 3,4-dihydroxyphenylalanine (DOPA); (5) 3,4-dihydroxybenzylamine (DHBA); (6) 3,4-dihydroxyphenylacetic acid (DOPAC); (7) dopamine.

Catechol concentrations were determined by standard curves based on peak heights. Recoveries were calculated and corrected for that of DHBA which was 75-85\%. Each tissue extract was assayed in triplicate with intra-assay variation $<5 \%$. The limit of detection was $0.2 \mathrm{pmol} / 0.05$ $\mathrm{ml}$ injected, corresponding to about $10 \mathrm{pmol} / \mathrm{g}$ myometrium. The number of animals used at each gestational age is given in parentheses. Data were analysed using the Wilcoxon rank Sum test (Snedecor \& Cochran, 1980) with values given as mean \pm s.d. $P<0.05$ was considered significant. The dopamine/3,4-dihydroxyphenylacetic acid (DOPAC) and dopamine/noradrenaline ratios were derived from raw data and their values may differ slightly from those that would be obtained simply by comparing mean values for dopamine, DOPAC and noradrenaline. 


\section{Results}

In no species at any gestational age was adrenaline detected (i.e. $<10 \mathrm{pmol} / \mathrm{g}$ ). Noradrenaline was consistently the major catecholamine although dopamine and 3,4-dihydroxyphenylacetic acid (DOPAC) were present in guinea-pig and particularly sheep uterus. In all tissues 3,4dihydroxyphenylalanine (DOPA) was present at $20-100 \mathrm{pmol} / \mathrm{g}$, but regional or pregnancyrelated changes were not observed for any species.

Rat

Noradrenaline was the major catecholamine and during pregnancy, its concentration, but not total uterine content, fell sharply to $<10 \%$ of the non-pregnant value $(P<0.05)$ (Table 1$)$. The largest changes occurred in perifetal myometrium while cervical noradrenaline showed greatest preservation. Total uterine content fell by about $40 \%$ in the term uterus $(P<0.05)$. Dopamine was present in the non-pregnant uterus at $43 \pm 9 \mathrm{pmol} / \mathrm{g}$ (4) corresponding to a (dopamine/noradrenaline) $\times 100$ value of $2 \cdot 78 \pm 0 \cdot 15 \%(4)$. With pregnancy dopamine levels fell rapidly until at term it was undetectable except in the cervical region $(24 \pm 9 \mathrm{pmol} / \mathrm{g}(4))$. DOPAC levels were not determined.

Table 1. Influence of pregnancy on noradrenaline concentration and total content in rat uterus

\begin{tabular}{lcc}
\hline \multicolumn{1}{c}{ Gestational age } & $\begin{array}{c}\text { Noradrenaline conc. } \\
\text { (pmol/g myometrium) }\end{array}$ & $\begin{array}{c}\text { Total uterine } \\
\text { noradrenaline } \\
\text { (pmol/uterus) }\end{array}$ \\
\hline Non-pregnant & $1575 \pm 130.5(4)$ & $722 \pm 24 \cdot 8(4)$ \\
12 days & $745 \pm 495 \cdot 7(3)$ & $595 \pm 144 \cdot 3(3)$ \\
17 days & $* 239 \pm 191 \cdot 5(4)$ & $* 510 \pm 57 \cdot 3(4)$ \\
21 days & & $* 420 \pm 111 \cdot 8(4)$ \\
$\quad \begin{array}{l}\text { Tubal myometrium } \\
\text { Perifetal myometrium }\end{array}$ & ${ }^{*} 93 \pm 18.5(4)$ & \\
Cervical & $* 176 \pm 70.9(4)$ & \\
\hline
\end{tabular}

\footnotetext{
Values are mean \pm s.d. for the no. of rats in parentheses. Full term is $21-22$ days.

* Significantly less than non-pregnant value $(P<0.05)$.

$\dagger$ Significantly less than values for other uterine regions at same gestational age $(P<0.05)$.
}

\section{Rabbit}

The predominant catecholamine was noradrenaline although small concentrations of dopamine were detected. Whole uterine mean noradrenaline concentration fell from $1633 \pm 177$ $\mathrm{pmol} / \mathrm{g}(4)$ in the non-pregnant uterus to $217 \pm 87 \mathrm{pmol} / \mathrm{g}$ at term $(4)(P<0.05)$. This decline reflected a more rapid fall in tubal and particularly perifetal myometrium with high concentrations maintained in the cervical region (Table 2). Total noradrenaline content remained unchanged until term when, as in the rat, it was reduced by about $40 \%(P<0.05)$. Dopamine was present at similar concentrations in all regions of the non-pregnant uterus with a mean concentration of $30 \pm 6$ $\mathrm{pmol} / \mathrm{g} \mathrm{(4).} \mathrm{With} \mathrm{pregnancy} \mathrm{it} \mathrm{fell} \mathrm{rapidly} \mathrm{and} \mathrm{was} \mathrm{undetectable} \mathrm{by} \mathrm{term.} \mathrm{The} \mathrm{(dopamine/noradren-}$ aline) $\times 100$ value, however, (while determinable) appeared constant at $2.82 \pm 1.71 \%$ (22) in all regions throughout pregnancy. DOPAC was not measured.

\section{Sheep}

It was not practically possible to analyse the whole uterus of the sheep. Although noradrenaline was the major catecholamine, very high concentrations of dopamine were detected at all times 
Table 2. Regional changes in noradrenaline concentration and total content in rabbit uterus with pregnancy

\begin{tabular}{|c|c|c|}
\hline $\begin{array}{l}\text { Gestational age } \\
\text { and uterine region }\end{array}$ & $\begin{array}{l}\text { Noradrenaline conc. } \\
\text { (pmol/g myometrium) }\end{array}$ & $\begin{array}{l}\text { Total uterine } \\
\text { noradrenaline } \\
\text { (nmol/uterus) }\end{array}$ \\
\hline Non-pregnant & & $21 \cdot 4 \pm 2.6(4)$ \\
\hline Tubal & $1648 \pm 295 \cdot 1$ & \\
\hline Mid & $1542 \pm 380.3(4)$ & \\
\hline Cervical & $1674 \pm 344 \cdot 3(4)$ & \\
\hline 21 days & & $22.9 \pm 3.5(4)$ \\
\hline Tubal & ${ }^{*} 543 \pm 397.8$ & \\
\hline Perifetal & ${ }^{*} 181 \pm 78.7(4)$ & \\
\hline Parafetal & $* 660 \pm 284 \cdot 1$ (4) & \\
\hline Cervical & $1625 \pm 317.5$ (4) & \\
\hline 27 days & & $18 \cdot 6 \pm 5 \cdot 0(3)$ \\
\hline Tubal & $* 413 \pm 151 \cdot 1$ & \\
\hline Perifetal & $* 77 \pm 16.6(3)$ & \\
\hline Parafetal & *266 $\pm 216.6(3)$ & \\
\hline Cervical & $888 \pm 437.8$ (3) & \\
\hline 31 days & & ${ }^{*} 13.2 \pm 4.1(4)$ \\
\hline Tubal & $* 73 \pm 64 \cdot 3(4)$ & \\
\hline Perifetal & $\dagger^{*} 12 \pm 3.3(4)$ & \\
\hline Cervical & $* 716 \pm 344 \cdot 1$ (4) & \\
\hline
\end{tabular}

Values are means \pm s.d. for the no. of animals in parentheses. Full term is 30 32 days.

* Significantly less than non-pregnant values $(P<0.05)$.

$\uparrow$ Significantly different from values for other uterine regions at same gestational age $(P<0.05)$.

Table 3. Concentrations of noradrenaline, dopamine and DOPAC, and relative levels of dopamine to noradrenaline and DOPAC in selected regions of non-pregnant and 125-135-day unilaterally pregnant sheep uterus

\begin{tabular}{|c|c|c|c|c|c|}
\hline Uterine sampie & $\begin{array}{c}\text { Noradrenaline } \\
\text { conc. } \\
\text { (pmol/g myometrium) }\end{array}$ & $\begin{array}{c}\text { Dopamine } \\
\text { conc. } \\
\text { (pmol/g myometrium) }\end{array}$ & $\begin{array}{c}\text { DOPAC } \\
\text { conc. } \\
\text { (pmol/g myometrium) }\end{array}$ & $\frac{\text { Dopamine } \ddagger}{\text { DOPAC }} \times 100$ & $\frac{\text { Dopamine } \ddagger}{\text { Noradrenaline }} \times 100$ \\
\hline \multicolumn{6}{|l|}{ Non-pregnant } \\
\hline Tubal & $3714 \pm 645.8(6)$ & $1307 \pm 619.4(6)$ & $5256 \pm 1868.0(6)$ & $24 \cdot 2 \pm 4.0(6)$ & $28 \cdot 1 \pm 17 \cdot 1(6)$ \\
\hline Middle & $4682 \pm 953.5(6)$ & $2139 \pm 922.0(6)$ & $5417 \pm 2328 \cdot 2(6)$ & $40 \cdot 3 \pm 9 \cdot 2(6)$ & $45.7 \pm 27.6(6)$ \\
\hline Cervical & $5045 \pm 1704.9(6)$ & $+521 \pm 205 \cdot 3(6)$ & $+2262 \pm 1232.5(6)$ & $35.2 \pm 17.6(6)$ & $+9.4 \pm 3.4(6)$ \\
\hline \multicolumn{6}{|c|}{$\begin{array}{l}\text { 125-135-day pregnant } \\
\text { (unilateral) }\end{array}$} \\
\hline \multicolumn{6}{|l|}{ 'Empty' horn } \\
\hline Tubal & ${ }^{*} 1028 \pm 220 \cdot 4(5)$ & $1176 \pm 719 \cdot 5(5)$ & $2653 \pm 864.5(5)$ & $36 \cdot 2 \pm 14 \cdot 1(5)$ & ${ }^{*} 127.7 \pm 87.6(5)$ \\
\hline Middie & $* 515 \pm 317.6(5)$ & ${ }^{*} 731 \pm 289.6(5)$ & $* 1451 \pm 412.8(5)$ & $47.0 \pm 23.0$ & $* 152.3 \pm 72.1(5)$ \\
\hline Cervical & ${ }^{*} 603 \pm 275 \cdot 3(5)$ & $451 \pm 324 \cdot 6(5)$ & $1341 \pm 642.6(5)$ & $26.9 \pm 13.5(5)$ & $* 77.2 \pm 32.1(5)$ \\
\hline \multicolumn{6}{|l|}{ Fetus-bearing horn } \\
\hline Tubal & ${ }^{*} 648 \pm 561.8(5)$ & $904 \pm 475.4(5)$ & $* 3056 \pm 1454.4(5)$ & $144.0 \pm 12.9(5)$ & ${ }^{*} 122.3 \pm 62.1(5)$ \\
\hline Perifetal & $t * 151 \pm 105.3(5)$ & $* 653 \pm 603 \cdot 1(5)$ & $* 1517 \pm 329.2(5)$ & $31.0 \pm 12.5(5)$ & $t * 496.2 \pm 141.7(5)$ \\
\hline
\end{tabular}

Values represented are mean \pm s.d. for the no. of animals in parentheses. Full term is $142-147$ days.

$\ddagger$ Relative values of dopamine derived from raw data for each experiment.

* Significantly less than respective non-pregnant value $(P<0.05)$.

+ Significantly different from values for other uterine regions at same stage $(P<0.05)$.

(Table 3). Noradrenaline concentrations, that were similar in all regions of non-pregnant uterus, fell sharply by $125-135$ days in all areas, particularly in the perifetal myometrium $(P<0 \cdot 01)$ (Table 3 ). Dopamine concentrations were greater than in any other species studied, the non-pregnant values representing nearly one-half that of noradrenaline, except in the cervix. By 125-135 days of pregnancy dopamine concentrations were unchanged except in the middle uterine regions where a fall of $66 \%$ had occurred $(P<0.05)$. The (dopamine/noradrenaline) $\times 100$ values were much 
greater than those observed in other species and were markedly higher in all pregnant uterine regions than non-pregnant (Table 3). DOPAC was present in all myometrial samples at high concentrations (Table 3).

\section{Human}

Noradrenaline was the major catecholamine in the isthmic myometrium and by term fell to $<10 \%$ of its non-pregnant value (Table 4). Dopamine and DOPAC were present at low levels in the non-pregnant isthmus but undetectable at term.

Table 4. Noradrenaline, dopamine and DOPAC concentrations, and relative levels of dopamine to noradrenaline and DOPAC in non-pregnant and term human isthmic myometrium

\begin{tabular}{lccccc}
\hline & $\begin{array}{c}\text { Noradrenaline } \\
\text { conc. }(\mathrm{pmol} / \mathrm{g} \\
\text { myometrium) }\end{array}$ & $\begin{array}{c}\text { Dopamine } \\
\text { conc. }(\mathrm{pmol} / \mathrm{g} \\
\text { myometrium) }\end{array}$ & $\begin{array}{c}\text { DOPAC } \\
\text { conc. }(\mathrm{pmol} / \mathrm{g} \\
\text { myometrium) }\end{array}$ & $\frac{\text { Dopamine } \dagger}{\text { DOPAC }} \times 100$ & $\frac{\text { Dopamine }}{\text { Noradrenaline }} \times 100$ \\
\hline $\begin{array}{l}\text { Non-pregnant } \\
\text { Term }\end{array}$ & $\begin{array}{l}775 \pm 381.7(7) \\
* 67 \pm 68.1(5)\end{array}$ & $39 \pm 25.9(7)$ & $50 \pm 27.0(7)$ & $82.3 \pm 33.9(7)$ & $5.2 \pm 1 \cdot 1(7)$ \\
\hline
\end{tabular}

Values are mean \pm s.d. for the no. of women in parentheses. N.D. $=$ not detectable.

- Significantly less than non-pregnant value $(P<0.01)$

$\dagger$ Values derived from raw data.

\section{Guinea-pig}

Guinea-pig uterus contained largely noradrenaline with moderately high concentrations of dopamine and DOPAC. Noradrenaline concentrations appeared constant throughout the oestrous cycle, but during pregnancy fell progressively between 10 and 40 days, and by 50 days were about $4 \%$ of the non-pregnant value $(P<0.01)$ and remained low until term (Text-fig. 2a). By comparison total noradrenaline content was not decreased significantly until 51 days $(P<0.05)$, and at term represented about one-half the value before pregnancy (Text-fig. $2 b$ ).

From the regional study it was apparent that the fall in noradrenaline concentration was related to the position of the developing fetus, decay being more rapid and extensive within perifetal tissue, with tubal and cervical values remaining relatively high even by term. The greater the number of fetuses within a uterine horn, the more rapid the decline of concentration in perifetal myometrium. Text-figure 3 shows noradrenaline changes with pregnancy along the length of the developing uterine horn carrying 2 fetuses. Term perifetal myometrium was nearly devoid of noradrenaline with values of $<50 \mathrm{pmol} / \mathrm{g}$ along the entire length.

Dopamine concentrations appeared unaffected by the oestrous cycle, and, as for rabbit and rat, but unlike sheep, during pregnancy they fell in line with those of noradrenaline (Text-fig. 2c). The term mean concentration of $5 \pm 4 \mathrm{pmol} / \mathrm{g}$ (8) reflected higher values in cervical and tubal myometrium (often $>25 \mathrm{pmol} / \mathrm{g}$ ), with dopamine undetectable in perifetal tissue. Total dopamine content was unchanged until late pregnancy when it fell to a term value around $10 \%$ of that of the non-pregnant uterus $(P<0.05)$ (Text-fig. 2d). The relative levels of dopamine and noradrenaline were similar throughout pregnancy except for a reduced value near term (Table 5). Guinea-pig uterus also contained large quantities of DOPAC, the (dopamine/DOPAC) $\times 100$ value falling dramatically with pregnancy (Table 5 ).

Post-partum recovery of uterine noradrenaline and dopamine was such that tissue concentrations increased initially, but recovery was incomplete by 11 weeks $(P<0 \cdot 05)$. Total noradrenaline content was unchanged from term values at 10 days post partum but at 11 weeks it was indistinguishable from the value in non-pregnant uterus. Total dopamine content was similar to values for non-pregnant uteri by 11 weeks (Text-figs $2 \mathrm{a}-\mathrm{d}$ ). The (dopamine/DOPAC) $\times 100$ 
(a) Noradrenaline conc.

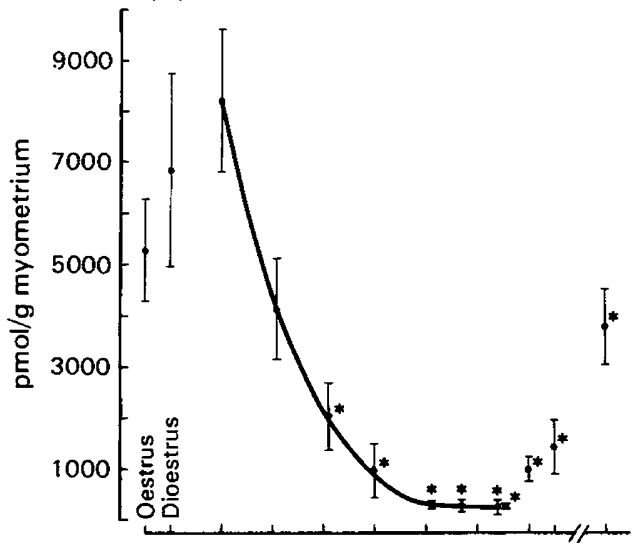

(c) Dopamine conc.

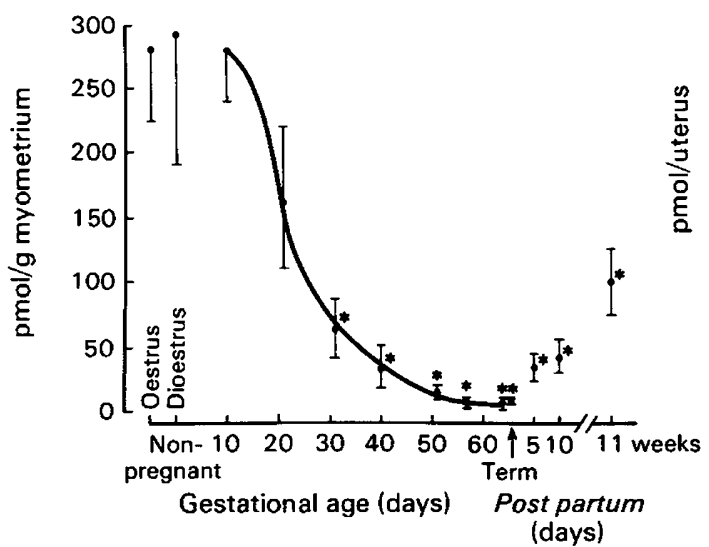

(b) Noradrenaline content

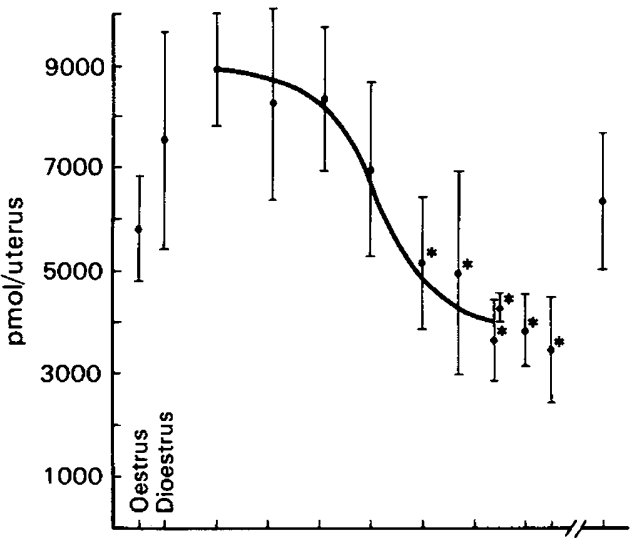

(d) Dopamine content

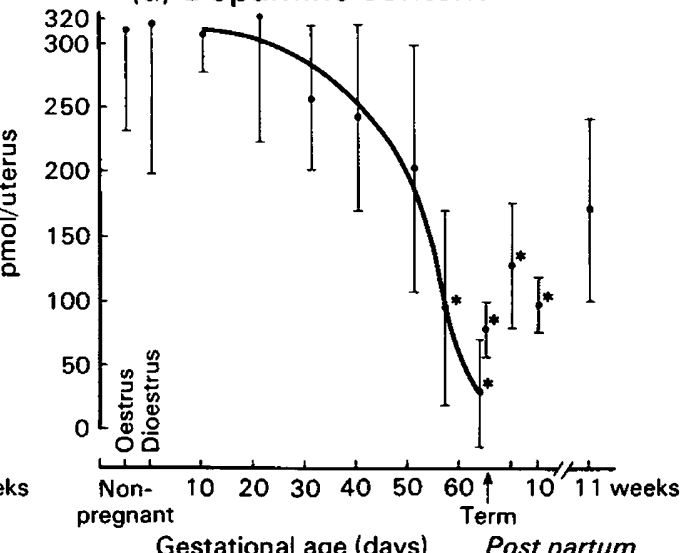

Gestational age (days) (days)

Text-fig. 2. Changes in concentration $(a, c)$ and total content $(b, d)$ of noradrenaline and dopamine in guinea-pig uterus with pregnancy. Full term is 66-68 days. Vertical bars represent s.d. of the mean of 6-8 determinations. *Significantly less than value at dioestrus $(P<0.05)$.

Table 5. Relative levels of dopamine to noradrenaline and DOPAC in guinea-pig uterus during pregnancy

\begin{tabular}{|c|c|c|}
\hline Gestational age & $\frac{\text { Dopamine }}{\text { Noradrenaline }} \times 100$ & $\frac{\text { Dopamine }}{\text { DOPAC }} \times 100$ \\
\hline Non-pregnant & $4.24 \pm 1.30(6)$ & $109.0 \pm 11.4(6)$ \\
\hline 10 days & $3.48 \pm 0.51(6)$ & $108.3 \pm 17.0(6)$ \\
\hline 21 days & $3.93 \pm 0.83(6)$ & $95.4 \pm 54.9(6)$ \\
\hline 31 days & $2.66 \pm 0.17(6)$ & $* 35.2 \pm 25.3(6)$ \\
\hline 40 days & $3.83 \pm 0.75(7)$ & $* * 10.9 \pm 7.0(7)$ \\
\hline 51 days & $4.05 \pm 0.83(6)$ & $* * 5.5 \pm 3.1(6)$ \\
\hline 57 days & $2.52 \pm 1.00(7)$ & $* * 2.5 \pm 2.5(7)$ \\
\hline 64 days & $* 1.89 \pm 0.92(8)$ & $* * 1.8 \pm 2.3(8)$ \\
\hline \multicolumn{3}{|l|}{ Immediately post partum } \\
\hline$(<6 \mathrm{~h})$ & $* 2.22 \pm 0.90(6)$ & $* * 4.8+1.7(6)$ \\
\hline 5 days post partum & $3.40 \pm 1.19(7)$ & $* * 20.5 \pm 10.8(7)$ \\
\hline 10 days post partum & $3.01 \pm 0.97(7)$ & $* * 32.4 \pm 7.8(7)$ \\
\hline 10 weeks post partum & $2.64 \pm 0.58(6)$ & $100.0 \pm 17.4(6)$ \\
\hline
\end{tabular}

Values represent means \pm s.d. derived from raw data for each experiment. No. of animals in parentheses. Full term is 66-68 days. 0.01 .

Values significantly different from non-pregnant value: ${ }^{*} P<0.05,{ }^{* *} P<$ 


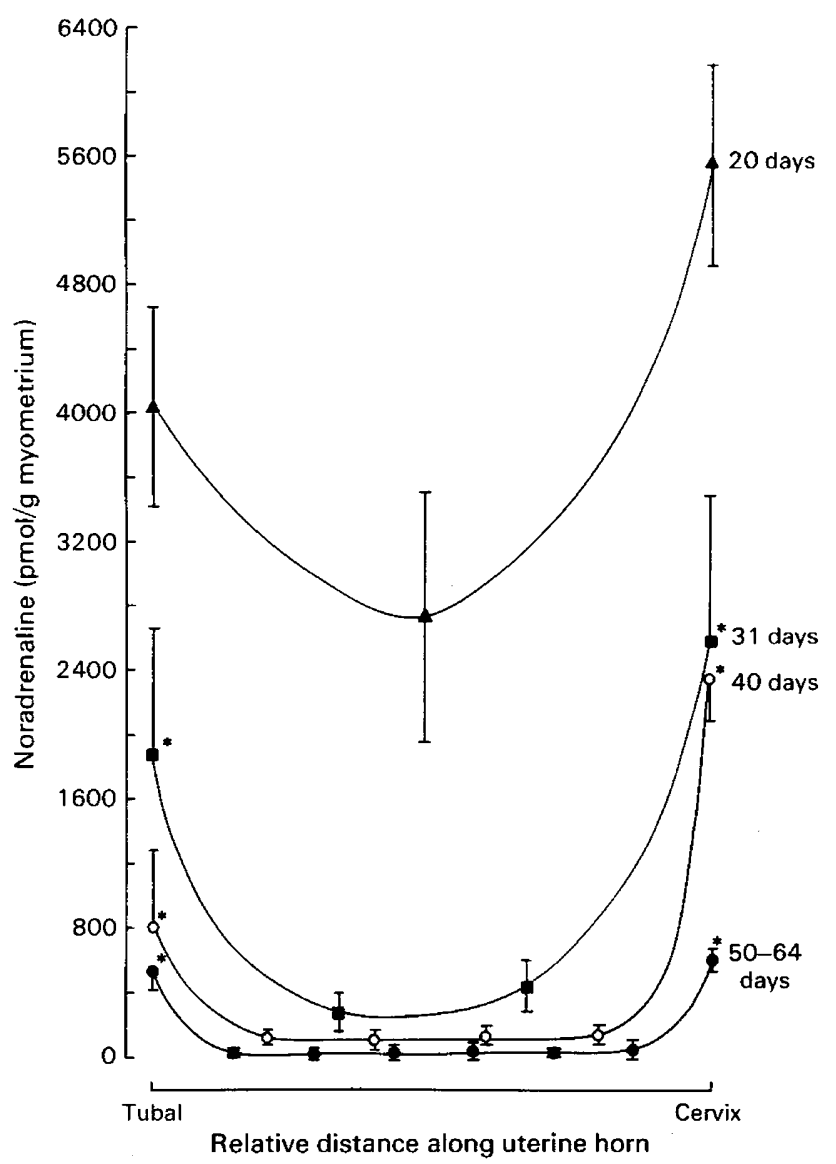

Text-fig. 3. Selected data from the guinea-pig study showing variation in noradrenaline concentration along the length of a uterine horn bearing 2 fetuses at the gestational ages indicated. Values are mean \pm s.d. for 3 or 4 guinea-pigs. *Significantly greater than values for other uterine regions at same gestational age $(P<0 \cdot 05)$.

value increased in the post-partum period to values similar to those of non-pregnant myometrium by 11 weeks (Table 5).

\section{Discussion}

Fluorescence histochemistry and fluorometric determinations in combination with denervation experiments revealed that uterine noradrenaline is contained within neurones (Sjoberg, 1967; Thorbert, 1978). Uterine concentration is therefore used as an index of adrenergic innervation density, whereas total content reveals change in innervation independent of smooth muscle mass.

The majority of previous studies on uterine catecholamine content utilized histofluorescencestaining techniques and fluorometric measurements which lack adequate catecholamine specificity (Shore \& Olin, 1958; Iversen, 1967; Swedin \& Brudin, 1968). This has led to discrepancies. For instance high concentrations of adrenaline have been found in the uterus of rat (Wurtman et al., 1963), sheep (Rexroad \& Barb, 1978) and rabbit (Cha et al., 1965), and in human uterus at levels above those of noradrenaline (Cha et al., 1965), while others have reported the uterus to be devoid of adrenaline (Sjoberg, 1967; Rosengren \& Sjoberg, 1968; Thorbert et al., 1978). Similarly, dopamine has been detected in (Swedin \& Brudin, 1968; Lackovic et al., 1982) and reported absent 
from (Sjoberg, 1967; Thorbert, 1978; Thorbert et al., 1978) uteri of various species. To resolve some of these inconsistencies the present study using HPLC with electrochemical detection permitted accurate identification and measurement of uterine catecholamines (Text-fig. 1).

The changes in uterine noradrenaline presented here are in general agreement with previous studies, which is as expected since the large quantities of noradrenaline limit problems of measurement (Sjoberg, 1967; Owman et al., 1975; Thorbert, 1978; Thorbert et al., 1979; More \& Nedjar, 1984). However, rat total uterine noradrenaline content has previously been reported as unchanged (Oskarsson, 1960) or increased (Cha et al., 1965) during pregnancy. Also, the reported increase in total noradrenaline content during early-mid pregnancy in guinea-pig (Owman et al., 1975 ) and rabbit (Rosengren \& Sjoberg, 1968) uteri was not observed here. Finally, by comparison with other reports (Owman et al., 1975) the cervical noradrenaline concentrations observed at term, especially in the rabbit are relatively high. The present observations therefore indicate that a regionally specific fall in uterine noradrenaline content, and therefore neuronal inactivation or degradation, is a consistent feature of pregnancy in animals of various species. This depletion is probably due both to steroid action on noradrenaline metabolism within short adrenergic neurones (Sjoberg, 1967; Rosengren \& Sjoberg, 1968; Falck et al., 1969; Owman et al., 1974; Thorbert et al., 1976; Thorbert, 1978) and disintegration of sympathetic nerves (Sporrong, Alm, Owman, Sjoberg \& Thorbert, 1978; Thorbert, 1978). The physiological significance of such a sympathetic withdrawal from the uterus, especially in perifetal myometrium, is unknown, but it is likely that the ability of the adrenergic innervation to elicit a contractile response is considerably limited. Another consequence is likely to be the beta-adrenergic supersensitivity response observed with pregnancy (Nakanishi, McLean, Wood \& Burnstock, 1969; Elmer, Alm \& Thorbert, 1980), resulting from reduced uptake and breakdown of catecholamines and potentially increased beta-receptor coupling and/or number (Harden, 1983).

An important distinction between the present measurements and those made by others is the absence of detectable adrenaline in any uterine tissue studied (Wurtman et al., 1963; Cha et al., 1965; Rexroad \& Barb, 1978). Adrenaline is able to relax the pregnant uterus (Zuspan et al., 1962) and could therefore be an important regulator of myometrial quiescence. Although a possible highly localized storage site cannot be eliminated, intrauterine adrenaline is unlikely to be a regulator of myometrial contractility.

Peripheral dopamine has been assumed to be only a precursor of noradrenaline. There is now growing evidence that it may function as a neurotransmitter and/or cotransmitter in some peripheral tissues (Lackovic \& Neff, 1983). For instance, dog kidney and paw pad appear to receive dopaminergic vasodilatory neurones (Bell \& Lang, 1973, 1979; Bell, Lang \& Laska, 1978; Dinerstein et al., 1979). Despite reports of uterine dopamine (Swedin \& Brudin, 1968; Lackovic et al., 1982) there is limited information on its potential functional significance. Infusion of dopamine into pregnant sheep at pharmacological $(>20 \mu \mathrm{g} / \mathrm{kg}$ per min) but not at physiological $(<2 \mu \mathrm{g} / \mathrm{kg}$ per min) doses increased intrauterine pressure (Fishburne et al., 1980). In man, similar effects were observed at physiological rates of infusion $(0 \cdot 4 \mu \mathrm{g} / \mathrm{kg}$ per min) (Urban et al., 1982).

The evaluation of the physiological significance of uterine dopamine requires assessment of whether it is purely a precursor, is located within neurones or some other cellular store, and whether functional dopamine receptors are present. In rat brain the concentration of dopamine metabolites DOPAC and homovanillic acid are dependent upon impulse frequency in dopaminergic neurones (Bacopoulos, Hattox \& Roth, 1979). Further, in some peripheral tissues of rat and human these catabolite levels are high and it was suggested that this reflected release of dopamine in preference for use in noradrenaline synthesis (Lackovic et al., 1982). Therefore, if dopamine present within guinea-pig and sheep uteri is the result of local synthesis, a potential transmitter function may be indicated by the high concentration of DOPAC. The precipitous fall in dopamine/DOPAC ratio in guinea-pig uterus with pregnancy (Table 5) is consistent with increased release and metabolism of dopamine.

However, non-neuronal cell types such as platelets (Olverman \& Sharman, 1983), small 
intensely fluorescent (SIF) 'chromaffin' cells (Bertler, Falck, Hillarp, Rosengren \& Torp, 1959) and mast cells (Falck, Nystedt, Rosengren \& Stenflo, 1964) have been shown to contain dopamine and may at least contribute to the observed tissue levels. Indeed, ruminant mast cells have been shown to store large quantities of dopamine (Falck et al., 1964) and if the 'chromaffin' cells observed by Bertler et al. (1959) in cow liver capsule were mast cells similar to those of the sheep uterus, then a myometrial mast cell incidence of $0.005 \%(\mathrm{v} / \mathrm{v})\left(10^{5}\right.$ cells $/ \mathrm{g}$ myometrium $)$ would entirely account for the dopamine concentrations observed here. In addition, if the contribution of SIF cells to uterine dopamine is significant, the higher cervical concentrations in rat and guinea-pig reported here may be due to SIF cells resident in peripheral sympathetic ganglia around the utero-vaginal junction (Owman et al., 1974). At present, therefore, there is insufficient information on the origin and function of uterine dopamine. However, the relative levels of myometrial dopamine and noradrenaline in the rat, rabbit and guinea-pig are very similar to those published for other tissues (Bell \& Gillespie, 1981) and are no greater than would be expected for dopamine associated with noradrenaline biosynthesis within adrenergic neurones (Bell \& Gillespie, 1981). This is not inconsistent with the DOPAC levels in guinea-pig uterus if dopamine is released as a cotransmitter with noradrenaline in a proportion equal to their axonal storage ratio. In comparison, the extremely high levels of dopamine relative to noradrenaline in sheep myometrium (Table 3) may reflect independent storage sites for dopamine and noradrenaline or possibly a species difference in the rate-limiting step for noradrenaline synthesis.

We thank Professor G. S. Dawes for laboratory facilities; Professor A. C. Turnbull for continued encouragement and assistance in obtaining human myometrial samples; and Ms S. Kitt for secretarial skills. S.J.A. is in receipt of an M.R.C. Studentship.

\section{References}

Bacopoulos, N.G., Hattox, S.E. \& Roth, R.H. (1979) 3,4Dihydroxyphenyl-acetic acid and homovanillic acid in rat plasma: possible indicators of central dopaminergic activity. Eur. J. Pharmacol. 56, 225-236.

Bell, C. \& Gillespie, J.S. (1981) Dopamine and noradrenaline levels in peripheral tissues of several mammalian species. J. Neurochem. 36, 703-706.

Bell, C. \& Lang, W.J. (1973) Neural dopaminergic vasodilator control in the kidney. Nature, New Biol. 246, 27-29.

Bell, C. \& Lang, W.J. (1979) Evidence for dopaminergic vasodilator innervation of the canine paw pad. Br.J. Pharmac. 67, 337-343.

Bell, C., Lang, W.J. \& Laska, F. (1978) Dopamine containing axons supplying the arterio-venous anastomoses of the canine paw pad. J. Neurochem. 31, 1329-1333.

Bengtsson, B. (1978) Estrogen and the relaxant effect of intramural noradrenaline on calcium induced contractures in depolarized rat uterus. Acta physiol. scand. 102, 368-373.

Bertler, A., Falck, B., Hillarp, N.-A., Rosengren, E. \& Torp, A. (1959) Dopamine and chromaffin cells. Acta physiol. scand. 47, 251-258.

Cha, K.-S., Lee, W.-C., Rudzik, A. \& Miller, J. W. (1965) A comparison of the catecholamine concentrations of uteri from several species and the alterations which occur during pregnancy. J. Pharmac. exp. Ther. 148, 9-13.

Dinerstein, R.J., Vannice, J., Henderson, R.C., Roth, L.J., Goldberg, L.I. \& Hoffman, P.C. (1979) Histofluorescence techniques provide evidence for dopa- mine containing neuronal elements in canine kidney. Nature, Lond. 205, 497-499.

Elmer, M., Alm, P. \& Thorbert, G. (1980) Electrical field stimulation of myometrial strips from non-pregnant and pregnant guinea-pigs. Acta physiol. scand. 108, 209-213.

Elvidge, H. (1972) Production of dated pregnant guineapigs without post-partum matings. J. Instit. Anim. Tech. 23, $111-117$.

Falck, B., Nystedt, T., Rosengren, E. \& Stenflo, J. (1964) Dopamine and mast cells in ruminants. Acta pharmac. toxicol. 21, 51-58.

Falck, B., Owman, C., Rosengren, E. \& Sjoberg, N.-O. (1969) Reduction by progesterone of the estrogeninduced increase in transmitter level of the short adrenergic neurones innervating the uterus. Endocrinology 84, 958-959.

Fishburne, J.I., Meis, P.J., Urban, R.B., Greiss, F.C., Wheeler, A.S., James, F.M., Swain, M.F. \& Rhyne, A.L. (1980) Vascular and uterine responses to dobutamine and dopamine in gravid ewe. Am. J. Obstet. Gynec. 137, 944-952.

Harden, T.K. (1983) Agonist induced desensitization of the beta-adrenergic receptor linked adenylate cyclase. Pharmac. Reviews 35, 5-32.

Isaac, P.F. \& Pennefather, J.N. (1969) The ovarian and hypogastric innervation of the guinea-pig uterus. Eur. J. Pharmac. 5, 384-390.

Iversen, L.L. (1967) The Uptake and Storage of Noradrenaline in Sympathetic Nerves, pp. 8-18. Cambridge University Press.

Lackovic, Z. \& Nefi, N.H. (1983) Evidence that 
dopamine is a neurotransmitter in peripheral tissues. Life Sci. 32, 1665-1674.

Lackovic, Z., Rezja, M. \& Neff, N.H. (1982) Catabolism of endogenous dopamine in peripheral tissues: is there an independent role for dopamine in peripheral neurotransmission? $J$. Neurochem. 38, 1453-1458.

Miller, M.D. \& Marshall, J.M. (1965) Uterine response to nerve stimulation; relation to hormonal status and catecholamines. Am. J. Physiol. 209, 859-865.

More, J. \& Nedjar, K. (1984) Intrinsic innervation of the ewe cervix and its variations during pregnancy. Histochemistry 80, 59-62.

Nakanishi, H., McLean, J., Wood, C. \& Burnstock, G. (1969) The role of sympathetic nerves in the control of the non-pregnant and pregnant human uterus. $J$. Reprod. Med. 11, 20-33.

Olverman, H.J. \& Sharman, D.F. (1983) Dopamine in the blood platelets of the sheep. Comp. Biochem. Physiol. 75C, 223-225.

Oskarsson, V. (1960) Influence of the ovarian hormones and denervation of the catecholamines of the rat uterus. Acta endocr., Copenh. 34, 38-44.

Owman, C., Sjoberg, N.-O. \& Sjostrand, N.-O. (1974) Short adrenergic neurons, a peripheral neuroendocrine mechanism. In Amine Fluorescence Histochemistry, pp. 47-66, Ed. M. Fujiwara. Igaku-Shoin, Tokyo.

Owman, C., Alm, P., Rosengren, E., Sjoberg, N.-O. \& Thorbert, G. (1975) Variations in the level of uterine norepinephrine during pregnancy in the guinea-pig. Am. J. Obstet. Gynec. 122, 961-964.

Rexroad, C.E. \& Barb, C.R. (1978) Contractile response of the uterus of estrous ewe to adrenergic stimulation. Biol. Reprod. 19, 297-305.

Rosengren, E. \& Sjoberg, N.-O. (1968) Changes in the amount of adrenergic transmitter in the female genital tract of rabbit during pregnancy. Acta physiol. scand. 72, 412-424.

Russe, W.M. \& Marshall, J.M. (1970) Uterine response to adrenergic nerve stimulation in the guinea-pig. Biol. Reprod. 3, 13-22.

Shore, P.A. \& Olin, J.S. (1958) Identification and chemical assay of Norepinephrine in brain and other tissues. J. Pharmacol. exp. Ther. 122, 295-300.
Sjoberg, N.-O. (1967) The adrenergic transmitter of the female reproductive tract: distribution and functional changes. Acta physiol. scand., Suppl. 305, 1-32.

Snedecor, G.W. \& Cochran, W.G. (1980) In Statistical Methods, pp. 144-145. Iowa State University Press, Ames.

Sporrong, B., Alm, P., Owman, C., Sjoberg, N.-O. \& Thorbert, G. (1978) Ultrastructural evidence for adrenergic nerve degeneration in the guinea-pig uterus during pregnancy. Cell Tiss. Res. 195, 189-193.

Swedin, G. \& Brudin, J.O. (1968) Distribution of noradrenaline in the genital organs of the female rat with a remark on dopamine in the cervix and vagina. Experientia 24, 1015-1016.

Thorbert, G. (1978) Regional changes in structure and function of adrenergic nerves in guinea-pig uterus during pregnancy. Acta obstet. gynaec. scand., Suppl. 79, 1-32.

Thorbert, G., Batra, S., Owman, C., Rosengren, E. \& Sjoberg, N.-O. (1976) Uterine norepinephrine levels as related to plasma and tissue progesterone in pseudopregnant rabbits. Endocrinology 99, 12071212.

Thorbert, G., Alm., P. \& Rosengren, E. (1978) Cyclic and steroid-induced changes in adrenergic neurotransmitter level of guinea-pig uterus. Acta obstet. gynaec. scand. 57, 45-48.

Thorbert, G., Alm, P., Bjorklund, A.B., Owman, C. \& Sjoberg, N.-O. (1979) Adrenergic innervation of the human uterus. Am. J. Obstet. Gynec. 135, 223-226.

Urban, J., Radwan, J., Laudanski, T. \& Akerlund, M. (1982) Dopamine influence on human uterine activity at term pregnancy. Br. J. Obstet. Gynaec. 89, 451-455.

Wurtman, R.J., Axelrod, J. \& Kopin, I.J. (1963) Uterine epinephrine and blood flow in pregnant and postparturient rats. Endocrinology 73, 501-503.

Zuspan, F.P., Cibils, L.A. \& Pose, S.V. (1962) Myometrial and cardiovascular responses to alterations in plasma epinephrine and norepinephrine. Am. J. Obstet. Gynec. 84, 841-851.

Received 9 August 1984 